\title{
A multidimensional social desirability inventory
}

\author{
LEONARD I. JACOBSON, RICHARD W. KELLOGG, ANA MARI CAUCE, and ROBERT S. SLAVIN \\ University of Miami, Coral Gables, Florida 39124
}

\begin{abstract}
The hypothesis that the need for social approval may be viewed most adequately as a multidimensional construct consisting of at least partially independent dimensions was evaluated. An inventory was created and tested that measured independently each of four factors identified as operative in previous research in this area. Based on a conception of the importance of attribution and denial as central elements in self-descriptive statements differing in social desirability value, four scales were created measuring the frequency of endorsement of statements comprising each of the following: the attribution of positive traits, the attribution of negative traits, the denial of positive traits, and the denial of negative traits. The inventory was designed also to control for the possible operation of both agreement and acceptance acquiescence. The data obtained provided strong support for the conceptualization delineated and for the inventory constructed.
\end{abstract}

In a recent analysis, Millham (1974) indicated that the need for social approval variable (Crowne \& Marlowe, 1964; Jacobson \& Ford, 1966) may be confounded. He identified two components of this response set, not identified originally, that determine performance on the Marlowe-Crowne social desirability scale (Crowne \& Marlowe, 1960). The two response sets are: the tendency to attribute socially desirable characteristics to the self and the tendency to deny socially undesirable characteristics.

Millham has suggested that these two characteristics may be only partially related. However, further analysis suggests that the construct may not be merely a bidimensional one. In fact, attribution and denial constitute a matrix consisting of the attribution of positive traits, the attribution of negative traits, the denial of positive traits, and the denial of negative traits. When these four factors are evaluated, it may be necessary to reconceptualize the need for social approval as a multidimensional construct, the basic elements of which have not previously been clearly identified.

The purpose of the present study was to construct a need for social approval inventory that measured independently each of the factors that comprise the assumed need for social approval matrix. The inventory was constructed so as to allow for the control of any possible effects of agreement and acceptance acquiescence response sets (Bentler, Jackson, \& Messick, 1971). As a result of the construction of such an instrument, it becomes possible not only to identify each of the relevant dimensions but to assess the extent to which they operate as factors of general importance. In addition, the relationship of the present inventory to other social desirability measures was determined.

The authors wish to acknowledge the assistance of Timothy J. Alper, Maria A. Prio, and Jan Robertson. Requests for reprints and copies of the inventory may be obtained from Leonard I. Jacobson, Department of Psychology, University of Miami, P. O. Box 248185, Coral Gables, Florida 33124.

\section{METHOD}

\section{Subjects}

The subjects were 412 male and female undergraduates enrolled in introductory psychology courses at the University of Miami.

\section{The Jacobson-Kellogg Self-Description Inventory}

Four scales comprise the Jacobson-Kellogg self-description inventory (SDI). The scores on these scales and the total score provide quantitative measures of the four aspects of social desirability identified. Specifically, they provide operational definitions of the extent to which subjects accept or deny traits differing in social desirability value (i.e., attribution of positive traits, attribution of negative traits, denial of positive traits, denial of negative traits).

Scale 1-Attribution of positive traits: Items for which the socially desirable response is "true." A true response is one in which the subject attributes to the self a socially desirable stem behavior:

"I always keep my promises."

"I obey all traffic laws."

Scale 2-Attribution of negative traits: Items for which the socially desirable response is "false." A true response is one in which the subject attributes to the self a socially undesirable stem behavior:

"I sometimes try to dodge responsibilities."

"I sometimes lie to make a better impression."

Scale 3-Denial of positive traits: Items for which the socially desirable response is "false." A true response is one in which the subject denies a socially desirable stem behavior:

"I am not always a good listener."

"I do not wake up fresh and rested every morning."

Scale 4-Denial of negative traits: Items for which the socially desirable response is "true." A true response is one in which the subject denies a socially undesirable stem behavior:

"I never blame others for my own mistakes."

"I never lie to get out of work."

The SDI was designed to control for the possible effects of both agreement acquiescence and acceptance acquiescence 
(Bentler, Jackson, \& Messick, 1971). Agreement acquiescence is defined as the tendency to agree with all items regardless of content. Acceptance acquiescence is defined as the tendency to agree with all self-descriptive items and to disagree with items that deny such characteristics.

Agreement acquiescence was controlled by keying the socially desirable response for the 68 items either "true" or "false" with equal frequency. Acceptance acquiescence was controlled within a balanced design in which the socially desirable response was keyed true or false with equal frequency for 34 attribution and 34 denial items. Thus, for 17 attribution and 17 denial items, the socially desirable response was true; for the remaining 17 of each, the socially desirable response was false.

\section{Inventory Construction}

An original pool of approximately 200 items was constructed. Of these, the investigators agreed that 100 of the items had content validity. The items were balanced in terms of true-false keying.

A 100-item scale was administered to 29 subjects. The reliability (Kuder-Richardson Formula 20) was .92 , and 80 of the items had point biserial (pbs) correlations for the appropriate scale significant beyond the .01 level. These 80 items were administered to a second sample of 70 subjects. The reliability was .89 , and 68 of the items had pbs correlations significant beyond the .01 level within each scale.

The 68 items were administered to a third sample of 116 subjects. The reliability for this administration was .91 , and all of the items attained pbs correlations significant beyond the .01 level. The mean number of desirable responses for the sample was $33.66(\mathrm{SD}=11.80)$.

The same 68 items were readministered to a fourth sample of 197 subjects. The reliability of the inventory was .90 and, once again, all of the items attained pbs correlations significant beyond the .01 level within each scale. The mean number of desirable responses for this sample was $32.61(\mathrm{SD}=11.25)$.

\section{RESULTS AND DISCUSSION}

The intercorrelations among the scales of the SDI for the final sample of 197 subjects are presented in Table 1. The table indicates a pattern of moderate correlations among the scales and a high correlation of each with total score. Table 2 presents the means and standard deviations for each of the scales. Analysis of variance indicated no effect of sex for any scale or for total SDI score.

For purposes of comparison, the SDI was correlated with both the Marlowe-Crowne social desirability scale (Crowne \& Marlowe, 1960) and the Edwards social desirability scale (Edwards, 1957). Given the similarities

Table 1

Intercorrelations Among the SDI Scales

\begin{tabular}{lcccc}
\hline Scale & SDI 1 & SDI 2 & SDI 3 & SDI 4 \\
\hline SDI 2 & .54 & & & \\
SDI 3 & .64 & .57 & & \\
SDI 4 & .61 & .66 & .54 & \\
SDI Total & .83 & .84 & .82 & .85 \\
\hline
\end{tabular}

Note $-N=197$
Table 2

Means and Standard Deviations of the Measures Employed

\begin{tabular}{lrr}
\hline Scale & M & SD \\
\hline SDI 1 & 9.46 & 3.35 \\
SDI 2 & 8.62 & 3.50 \\
SDI 3 & 6.68 & 3.18 \\
SDI 4 & 7.82 & 3.52 \\
SDI Total & 32.59 & 11.30 \\
Marlowe-Crowne SD & 15.02 & 5.96 \\
Edwards SD & 30.17 & 5.83 \\
\hline
\end{tabular}

Note $-N=197$

of approach of the former and the SDI, a moderate to high correlation between the two was expected. Similarly, given previous correlations obtained between the Marlowe-Crowne and the Edwards scale, a low to moderate correlation between the Edwards and SDI was anticipated. The correlation of the SDI total score with the Marlowe-Crowne actually obtained was .82 , and .42 between the SDI and Edwards scale. Both correlations were highly significant $(p<.001)$ and in accord with expectations.

These data provide strong support for the conception of social desirability as a multidimensional construct. The inventory described here provides operational definitions of the attribution and denial aspects of the need for social approval matrix. In addition, the data provide unequivocal support for Millham's (1974) hypothesis that these dimensions are only partially related and amenable to independent assessment.

As a result of the construction of the present inventory, it is now possible to assess quantitatively four fundamental dimensions comprising the need for social approval matrix. These factors may be evaluated individually or in conjunction with each other as in traditional social desirability scales.

\section{REFERENCES}

Bentler, P. M., Jackson, D. N., \& Messick, S. Identification of content and style: A two-dimensional interpretation of acquiescence. Psychological Bulletin, 1971, 76, 186-204.

Crowne, D. P., \& Marlowe, D. A new scale of social desirability independent of psychopathology. Journal of Consulting Psychology, 1960, 24, 349-354.

CROWNE, D. P., \& MARLOWE, D. The approval motive. New York: Wiley, 1964.

EDWARDs, A. L. The social desirability variable in personality assessment and research. New York: Dryden, 1957.

JACOBSON, L. I., \& FoRD, L. H., JR. Need for approval, defensive denial, and sensitivity to cultural stereotypes. Journal of Personality, 1966, 34, 596-609.

Millham, J. Two components of need for approval score and their relationship to cheating following success and failure. Journal of Research in Personality, 1974, 8, 378-392.

(Received for publication September 3, 1976.) 